mass spectrometry test was used to determine the concentration of illegal drugs, nicotine and caffeine.

Results No donors reported being a drug user or an active smoker. $33 \%$ of donors admitted consuming caffeine.

No illegal drugs were found. Caffeine was found in 50\% of breastmilk $(272,8 \pm 560,5 \mathrm{ng} / \mathrm{ml})$, in $78 \%$ of urine $(455,27 \pm$ $510,5 \mathrm{ng} / \mathrm{ml})$ and $78 \%$ of hair samples $(1,76 \pm 1,58 \mathrm{ng} / \mathrm{mg})$. Caffeine was found in $25 \%$ of donors who denied consuming caffeine $(361 \pm 528 \mathrm{ng} / \mathrm{ml})$.

Nicotine was found in $33 \%$ of hair samples and cotinine in $50 \%$ of urine and $33 \%$ of hair samples. Both substance levels were under the threshold of significant ambiental exposition.

Conclusions We found a good agreement between self-report and breastmilk, urine and hair analysis for illegal drug and tobacco use. We found a moderate agreement for caffeine, although breastmilk concentrations were not of concern for newborns.

\section{PO-0591 SUPPORTING EARLY BREASTMILK EXPRESSION ON THE NEONATAL UNIT - ARE WE DOING ENOUGH?}

${ }^{1}$ A Hickey, ' ${ }^{1} \mathrm{~K}$ Tavener, ${ }^{2} \mathrm{~V}$ Olivera. ${ }^{1}$ Paediatrics, King's College Hospital, London, UK;

${ }^{2}$ Paediatrics, Guys and St Thomas' Hospital, London, UK

10.1136/archdischild-2014-307384.1232

Background and aims When breastfeeding is delayed, prompt breast-milk expression facilitates establishment and maintenance of lactation. On neonatal units, the recommended UNICEF target of all mothers achieving early milk expression within $6 \mathrm{~h}$ of birth is often not achieved. For critically ill infants, breast milk is particularly beneficial due to its nutritional and immunological benefits. Clinical practices that positively affect timely initiation are poorly described. Our aim was to investigate these practices. Methods A cross-sectional survey was performed on a tertiary neonatal unit to assess lactation and breastfeeding support provided to mothers of term and preterm infants. Anonymous questionnaires were distributed, between days 3-7 postpartum.

Results Of 79 participants, 53\% were advised about breast-milk antenatally. Overall, $90 \%$ of mothers were helped to handexpress but only $11 \%$ within $6 \mathrm{~h}$ of birth. Breastfeeding nurses and midwives provided most advice but neonatal nurses were involved in only $10 \%$ of episodes. The likelihood of early expression was lower for mothers of preterm infants and in mothers who had not done kangaroo care but not significantly. Maternal perception of support was positive in $90 \%$ of cases.

Conclusion The survey demonstrated a large discrepancy between recommended levels of support and actual practice. Questions about the feasibility of conforming to Unicef recommendations in neonatal units remain. Further analysis of the factors that impeded early expression is needed. It may well be that in mothers whose infants require neonatal care, there are entirely valid reasons for some delay in initiation of expression.

\section{PO-0592 DISTINGUISHING CONGENITAL COMBINED PITUITARY HORMONE DEFICIENCY FROM BILIARY ATRESIA AS A CAUSE OF CHOLESTASIS IN INFANTS}

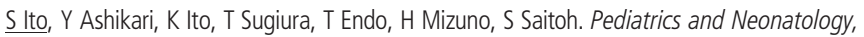
Graduate School of Medical Sciences Nagoya City University, Nagoya, Japan

10.1136/archdischild-2014-307384.1233

Background and aims Neonatal cholestasis is caused by either biliary atresia or intrahepatic cholestasis. Congenital combined pituitary hormone deficiency (CPHD) is a rare disease and a recognised cause of intrahepatic cholestasis. It is important to differentiate cholestasis due to this entity from cholestasis due to biliary atresia, since both diseases can cause jaundice at about 1 month of age. However, doing so in a timely fashion remains a diagnostic dilemma.

This retrospective study was performed to clarify differences between cholestasis due to congenital CPHD and cholestasis due to biliary atresia.

Methods From 2004 to 2010, 4 infants (2 boys and 2 girls) with cholestasis due to congenital CPHD were admitted to Nagoya City University Hospital. Head magnetic resonance imaging of the 4 infants revealed an invisible pituitary stalk; 3 of these 4 infants had an ectopic posterior pituitary. Liver biopsy was performed in 3 of the 4 infants, and histological findings included giant cell hepatitis. Findings from these 4 infants were then compared with those from 55 infants treated in our hospital for cholestasis due to biliary atresia.

Results The results showed a significant difference in mean gamma-glutamyl transpeptidase levels between the two groups of infants (115.0 IU/1 vs. $553.0 \mathrm{IU} / 1$, respectively).

Conclusions The gamma-glutamyl transpeptidase level was found to be useful for distinguishing congenital CPHD from biliary atresia as the cause of cholestasis. The diagnosis of hypopituitarism should always be considered in infants with unexplained neonatal hepatitis.

\section{PO-0593 HOW DO ANTIBIOTICS AFFECT THE DEVELOPMENT OF THE FAECAL MICROBIOTA OF THE NEONATE?}

${ }^{1}$ MV Jiménez Cabanillas, ${ }^{2} E$ Martín Álvarez, ${ }^{1} B$ García Cuerva, ${ }^{3}$ J Fonollá, ${ }^{3} \mathrm{M}$ Olivares, ${ }^{2} \mathrm{JA}$ Hurtado Suazo. ${ }^{1}$ Pediatrics, Hospital Virgen de Las Nieves, Granada, Spain; ${ }^{2}$ Neonatology, Hospital Virgen de Las Nieves, Granada, Spain; ${ }^{3}$ Department of Nutrition and Health, Biosech Life, Granada, Spain

\subsection{6/archdischild-2014-307384.1234}

Objective Evaluating the effects that the antibiotic, administered in the first two weeks of life, over the newborn's composition of the intestinal microbiota and its influence on other ages of the infant.

Design Study of the prospective cohorts carried outbetween January 2013-February 2014 in the Neonatal Unit of a third levelhospital. 3 stool samples are collected: M1 (admission), M2 (discharge), M3 (1st month of life). It isanalysed the influence of the antibiotic parenteral treatment in the first 15 days of life on the intestinal colonisation of the 4 bacterial groups: Bacteroids, Clostridium, Lactobacillus and Escherichia Coli, using molecular biology techniques (qPCR).

Results 27 neonates have been enrolled in the studio:15 babies have received parenteral antibiotic and 12 babies have not. The content of Lactobacillus when discharge is lower in those who have received antibiotic treatment $\left(9,28 \times 10^{2} \mathrm{CFU} / \mathrm{g}\right.$ vs $7,21 \times$ $\left.10^{3} \mathrm{CFU} / \mathrm{g} ; \mathrm{p} 0,005\right)$. This difference is the same in a month $\left(1,79 \times 10^{2} \mathrm{CFU} / \mathrm{g}\right.$ vs $\left.4,77 \times 10^{5} \mathrm{CFU} / \mathrm{g} ; \mathrm{p} 0,16\right)$. The influence of the antibiotic treatment over the colonisation of the rest of groups studied has not been demonstrated.

Conclusions The use of antibiotic in the neonatal period has shown tohave an influence on the neonate's intestinal colonisation process, producing a decrease in the content of lactobacillus (bacterial group related to beneficial effects for the guest). This research is considered to be the basis of future strategies in order to care these neonates (specially based on probiotics). 